\title{
Intercropping oilseed rape with wheat and releasing Harmonia axyridis sex pheromone in Northern China failed to attract and support natural enemies of aphids
}

\author{
Séverin Hatt ${ }^{(1,2,3)}$, Qingxuan $\mathrm{Xu}^{(1,2)}$, Frédéric Francis ${ }^{(2)}$, Julian Chen ${ }^{(1)}$ \\ (1) State Key Laboratory for Biology of Plant Diseases and Insect Pests, Institute of Plant Protection, Chinese Academy of \\ Agricultural Sciences, 2 West Yuanmingyuan Rd., Haidian District, 100193 Beijing, China. E-mail: Julian Chen: jlchen@ \\ ippcaas.cn \\ (2) Functional and Evolutionary Entomology, Terra Research and Teaching Center, Gembloux Agro-Bio Tech, University of \\ Liège, Passage des Déportés 2, 5030 Gembloux, Belgium.E-mail: frederic.francis@uliege.be \\ (3) Terra AgricultureIsLife, Gembloux Agro-Bio Tech, University of Liège, Passage des Déportés 2, 5030 Gembloux, \\ Belgium.
}

Received 19 July 2018, accepted 3 April 2019, available online 26 April 2019.

This article is distributed under the terms and conditions of the CC-BY License (http://creativecommons.org/licenses/by/4.0)

Description of the subject. Increasing plant diversity with flowering plants and releasing semiochemicals did not attract and support natural enemies of insect pests for biological control.

Objectives. We tested the effect of intercropping oilseed rape with wheat, and releasing the sex pheromone of the ladybeetle Harmonia axyridis, on the abundance of aphids' natural enemies.

Method. Four treatments repeated three times were compared in an experimental field in Langfang (Hebei, China): (i) oilseed rape-wheat intercropping + sex pheromone release, (ii) oilseed rape-wheat intercropping solely, (iii) pure-stand wheat and (iv) pure-stand oilseed rape. Ladybeetles, hoverflies, lacewings and parasitoids were pan-trapped during nine weeks in spring 2016 in each treatment.

Results. A diversity of natural enemy species was trapped. However, intercropping and the release of the sex pheromone did not significantly increase their abundance compared to pure-stands.

Conclusions. The results are discussed in regard to technical issues to improve the experimental protocol for future research in China.

Keywords. Biological control, Triticum aestivum L., Brassica napus L., predators, parasitoids, chemical ecology.

Associer du colza avec du blé et diffuser la phéromone sexuelle de Harmonia axyridis en Chine du Nord n'a pas permis d'attirer les ennemis naturels des pucerons

Description du sujet. Un accroissement de la diversité végétale par la présence de fleurs et la diffusion des molécules sémiochimiques en champs n'ont pas augmenté l'attraction des populations d'ennemis naturels en vue du contrôle biologique des insectes ravageurs.

Objectifs. Nous avons testé l'effet de l'association du blé avec du colza et la diffusion de la phéromone sexuelle de la coccinelle Harmonia axyridis sur l'abondance en ennemis naturels aphidiphages.

Méthode. Quatre traitements furent répétés trois fois dans un champ expérimental à Langfang (Hebei, Chine) : (i) association blé-colza + diffusion de la phéromone sexuelle, (ii) association blé-colza uniquement, (iii) culture pure de blé, (iv) culture pure de colza. Coccinelles, syrphes, chrysopes et parasitoïdes furent collectés dans chaque traitement durant neuf semaines au printemps 2016.

Résultats. Une diversité d'ennemis naturels fut collectée. Néanmoins, l'association de culture et la diffusion du sémiochimique n'accrurent pas leur abondance en comparaison aux cultures pures.

Conclusions. Les causes de cette absence d'effet sont discutées en vue de futures expériences qui testeraient ces mêmes techniques pour développer les méthodes de lutte biologique en Chine.

Mots-clés. Lutte biologique, Triticum aestivum L., Brassica napus L., prédateurs, parasitoïdes, écologie chimique. 


\section{INTRODUCTION}

Wheat (Triticum aestivum L.) is one of the main crops cultivated in Northern China. Intercropping wheat with another crop can help reduce the abundance of their insect pests (e.g. aphids [Hemiptera: Aphididae]) compared to pure-stands, despite the density of their natural enemies not always increasing in such intercropping fields (Lopes et al., 2016a). Nevertheless, the stability of biological control would benefit from a high density and diversity of insect pests' natural enemies (Letourneau et al., 2009). Hence, the present research explored ways to favor the attraction and support of aphid predators and parasitoids in intercropping systems.

Many aphid natural enemies are pollen and nectar feeders in addition to prey food (Lundgren, 2009). For some of them, notably hoverflies (Diptera: Syrphidae) and parasitoids (Hymenoptera: Braconidae), floral resources even provide their main food at the adult stage. Among other flowering crops, oilseed rape Brassica napus L. (Brassicaceae) is visited by aphid predators and parasitoids, and its nectar and pollen can enhance their fitness (Ali et al., 2011; Varennes et al., 2016). Hence, we tested the benefits of oilseed rape in terms of natural enemy attraction and support when it is intercropped with wheat. Such an intercropping has been studied previously, but only wheat crops were investigated and interactions between natural enemies and oilseed rape were ignored (Wang et al., 2009; Wang et al., 2011).

Semiochemicals are used by insects to locate their prey or hosts, host plants or conspecifics. Previous studies reported positive effects on aphid biological control when intercropping was associated with the release of synthesised semiochemicals ( $\mathrm{Xu}$ et al., 2018). Fassotte et al. (2014) identified the composition of the sex pheromone of the ladybeetle Harmonia axyridis (Coleoptera: Coccinellidae) and reported the attraction of males when the pheromone was released in a controlled environment. Thus, we also tested the benefits of the release of this sex pheromone in terms of ladybeetle attraction in intercropping fields.

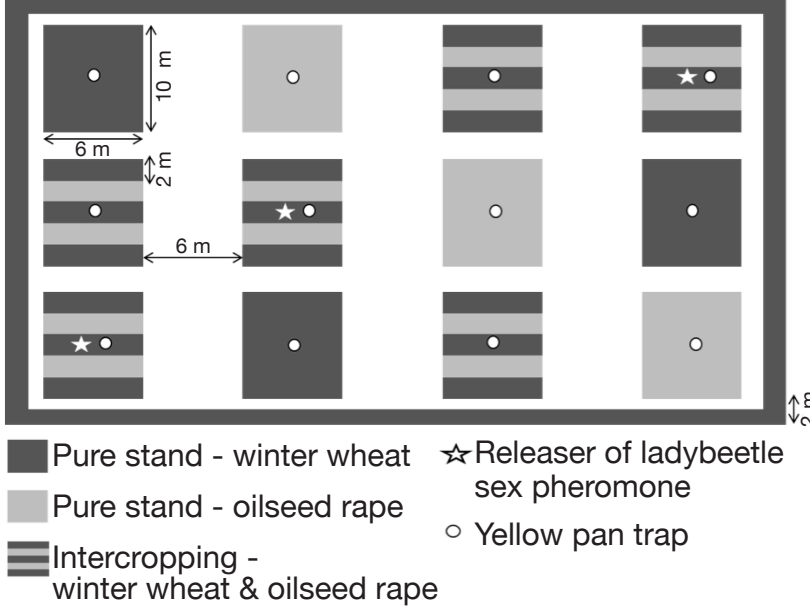

Figure 1. Experimental design (Langfang, Hebei, China [39 $\left.\left.30^{\prime} \mathrm{N}, 116^{\circ} 37^{\prime} \mathrm{E}\right]\right)$ - Plan expérimental (Langfang, Hebei, Chine [39³0'N, $116^{\circ} 37$ E]).

Discussion). Treatments were:

- oilseed rape-wheat intercropping + the release of $H$. axyridis sex pheromone;

- oilseed rape-wheat intercropping solely;

- pure-stand wheat;

- pure-stand oilseed rape.

Intercropping plots were a succession of three strips of wheat and two strips of oilseed rape $(2 \mathrm{~m} \times 6 \mathrm{~m}$ each). The wheat variety was Zhongmai 175 and the oilseed rape variety was Qinyou 2. No pesticides were used in the entire experimental area. The field was regularly irrigated.

The sex pheromone of $H$.axyridis was prepared in $\mathrm{n}$-hexane (10 ml solution, Table 1). It was released in the field from rubber septa that were inserted inside iron boxes with holes (one rubber septum per box). One box was placed in the middle of each plot of the treatment "oilseed rape-wheat intercropping + the release of $H$. axyridis sex pheromone", fixed to a $1 \mathrm{~m}$ high stick. Fifty $\mu 1$ of the solution was added every three weeks in each rubber septum. Fifty $\mu 1$ of solution represents the

\section{MATERIALS AND METHODS}

Twelve plots (four treatments repeated three times, $10 \mathrm{~m} \times 6 \mathrm{~m}$ each) were sown on 13-15 October 2015 in an experimental field in Langfang (Hebei, China [39 30' $\left.\mathrm{N}, 116^{\circ} 37^{\prime} \mathrm{E}\right]$ ) (Figure 1). Oilseed rape was re-sown on 29 March 2016 because the first seedlings froze at the cotyledon stage during winter (see
Table 1. Composition of the synthesised blend of the sex pheromone of Harmonia axyridis for $10 \mathrm{ml}$ of solution - Composition de la phéromone sexuelle d'Harmonia axyridis synthétisée pour $10 \mathrm{ml}$ de solution.

\begin{tabular}{lcll}
\hline Compound & Quantity & Purity & Origin \\
\hline$\beta$-caryophyllene & $549.0 \mu 1$ & $97 \%$ & Extracted from Nepeta cataria L. $^{1}$ \\
$\alpha$-humulene & $60.0 \mu 1$ & $98 \%$ & Sigma-Aldrich, Bornem, Belgium \\
methyl eugenol & $13.0 \mu 1$ & $99 \%$ & Sigma-Aldrich, Bornem, Belgium \\
$\beta$-elemene & $9.5 \mu 1$ & $98 \%$ & Isobionics, Geleen, The Netherlands \\
\hline
\end{tabular}

${ }^{1}$ see Fassotte et al., 2014 
quantity of semiochemicals released by $50 \mathrm{H}$. axyridis females in 15 days (Fassotte et al., 2014). A previous trial conducted in Belgium showed that septum releases a significant amount of semiochemicals during 30 days in fields (Fassotte et al., unpublished data).

Insects were collected every week from 5 April to 7 June 2016 with one yellow pan trap placed in the middle of each plot and by following the method described by Hatt et al. (2017a). Trapped aphidophagous lacewings (Neuroptera: Chrysopidae), ladybeetles, hoverflies and parasitoids were identified to species level.

To analyze the effect of treatments on the abundance of the trapped natural enemies (lacewings, ladybeetles, hoverflies and parasitoids separately, as well as $H$.axyridis), generalized linear mixed effect models (GLMM) with Poisson error distribution (treatments as fixed factors and the plots as random ones) were fitted. Data overdispersion was tested and when it occurred, GLM with negative binomial error distribution were fitted instead (Ver Hoef et al., 2007). For every selected model, the effect of the fixed factors was tested using a likelihood-ratio test $(p<0.05)$ and pair-wise comparisons were carried out with a Tukey post-hoc test. All statistical analyses were performed with R software (R Core Team, 2017).

\section{RESULTS}

Parasitoids were the most numerous natural enemies with 11 species trapped, and among them Aphidius gifuensis (Hymenoptera: Braconidae) was the most abundant (Table 2). Ladybeetles were also relatively abundant and among seven species, $H$.axyridis and Propylea 14 punctata (Coleoptera: Coccinellidae) represented almost $90 \%$ of individuals (Table 2). In comparison, hoverflies were rare; Eupeodes corollae (Diptera: Syrphidae) and Episyrphus balteatus (Diptera: Syrphidae) were the most abundant (Table 2). Individuals from the only lacewing species, Chrysoperla carnea (Neuroptera: Chrysopidae), were almost absent (Table 2).

Only the abundance of ladybeetles was significantly affected by the treatments $\left(\mathrm{df}=3 ; X^{2}\right.$-value $=17.4$; $p$-value $<0.001)$. They were significantly less abundant in the pure-stand oilseed rape compared to the other treatments (Table 2, Figure 2). However, no significant difference in the abundance of $H$.axyridis was found between the treatments $\left(\mathrm{df}=3 ; X^{2}\right.$-value $=$ 2.43; $p$-value $=0.489$; Table 2). The abundances of hoverflies $\left(\mathrm{df}=3 ; X^{2}\right.$-value $=1.45 ; p$-value $\left.=0.694\right)$ and parasitoids $\left(\mathrm{df}=3 ; X^{2}\right.$-value $=1.38 ; p$-value $=$ 0.710 ) were not significantly different between the treatments and the too little numbers of lacewings did not allow performing of the analysis (Table 2, Figure 2).

\section{DISCUSSION}

Ahigh diversity of natural enemies was trapped.Among them, few species represented the very large majority of individuals. Our results are in accordance with previous research on intercropping conducted in China (Lopes et al., 2014). Most of these species are also commonly found in West-European fields (Hatt et al., 2017b), except for A.gifuensis that has never been recorded in Belgium (Lopes et al., 2016b) although it is a very common and abundant aphid parasitoid in China (Lopes et al., 2014; Ali et al., 2018).

Intercropping oilseed rape with wheat did not allow attracting and supporting of a higher abundance of aphidophagous natural enemies compared to purestands. It is suspected that this result was due to oilseed rape plants not growing properly in the field and at the end of the experiment in mid-June, they had not bloomed. Thus, the expected floral resources that could have attracted and sustained pollen and nectar feeders were absent. The phenology of natural enemies was relatively similar between treatments (Figure 2). In the absence of flower resources, it is suspected that plant colonization by aphids (data not shown) drove natural enemy abundance in the field during the sampling period.

The present experiment is the first to grow oilseed rape in the Langfang experimental station. Indeed, in China, oilseed rape is generally cultivated in the central and southern regions that rarely face freezing temperatures over long period. In the present experiment, temperature was on average below $0{ }^{\circ} \mathrm{C}$ from December to February, with the coldest day at $-20{ }^{\circ} \mathrm{C}$ in January. Consequently, oilseed rape seedlings suffered from freezing during the winter and had to be re-sown in spring. To survive long periods of freezing temperatures, oilseed rape should have reached the 6-8 true-leaf stage (Diepenbrock, 2000), which was not the case here. As for the plants re-sown in the end of March, they did not elongate and bloom. The short spring season occurring in Northern China, characterized by a rapid increase of temperature (average temperature reached $30{ }^{\circ} \mathrm{C}$ in the end of May), may have prevented the proper development of the oilseed rape plants sown in spring (Sidlauskas \& Bernotas, 2003). For a future trial in Langfang, oilseed rape should be sown much earlier (e.g. at the end of August or the beginning of September).

The release of the sex pheromone of $H$.axyridis did not significantly increase the density of this species, which was the most abundant ladybeetle trapped (Table 2). This result suggests that the sex pheromone does not attract them from a long distance in open environment. The sex pheromone may be more involved in the recognition of mating partners at a short distance, along with other visual and tactical cues 
Table 2. Abundance and diversity of natural enemies trapped in the different treatments - Abondance et diversité des ennemis naturels piégés dans chaque traitement.

\begin{tabular}{|c|c|c|c|c|c|c|}
\hline Ennemies trapped & $\begin{array}{l}\text { Intercropping + } \\
\text { semiochemical }\end{array}$ & Intercropping & Oilseed rape & Wheat & Total & $\%$ \\
\hline Lacewings (Chrysopidae) & 3 & $\mathbf{0}$ & 1 & 2 & 6 & \\
\hline Chrysoperla carnea & 3 & 0 & 1 & 2 & 6 & 100 \\
\hline Ladybeetles (Coccinellidae) & $65^{\mathrm{a}}$ & $56^{\mathrm{a}}$ & $19^{b}$ & $63^{\mathrm{a}}$ & 203 & \\
\hline Harmonia axyridis & 26 & 33 & 7 & 30 & 96 & 47.3 \\
\hline Propylea 14 punctata & 36 & 19 & 2 & 26 & 83 & 40.9 \\
\hline Coccinella 7 punctata & 1 & 4 & 6 & 3 & 14 & 6.9 \\
\hline Hippodamia variegata & 2 & 0 & 3 & 2 & 7 & 3.4 \\
\hline Adalia decempuctata & 0 & 0 & 0 & 1 & 1 & 0.5 \\
\hline Chilocorus renipustalatus & 0 & 0 & 1 & 0 & 1 & 0.5 \\
\hline Oenopia conglobata & 0 & 0 & 0 & 1 & 1 & 0.5 \\
\hline Hoverflies (Syrphidae) & $5^{a}$ & $9^{a}$ & $9^{a}$ & $6^{a}$ & 29 & \\
\hline Eupeodes corollae & 3 & 4 & 7 & 3 & 17 & 58.7 \\
\hline Episyrphus balteatus & 2 & 4 & 2 & 2 & 10 & 34.5 \\
\hline Melanostoma mellinum & 0 & 0 & 0 & 1 & 1 & 3.4 \\
\hline Sphaerophoria scripta & 0 & 1 & 0 & 0 & 1 & 3.4 \\
\hline Parasitoids (Braconidae) & $76^{\mathrm{a}}$ & $67^{\mathrm{a}}$ & $101^{\mathrm{a}}$ & $55^{\mathrm{a}}$ & 299 & \\
\hline Aphidius gifuensis & 38 & 40 & 58 & 43 & 179 & 59.9 \\
\hline Diaeretiella rapae & 4 & 2 & 33 & 2 & 41 & 13.7 \\
\hline Aphidius funebris & 18 & 14 & 2 & 0 & 34 & 11.4 \\
\hline Aphidius rhopalosiphi & 5 & 5 & 4 & 6 & 20 & 6.7 \\
\hline Aphidius uzbekistanicus & 6 & 4 & 2 & 3 & 15 & 5.0 \\
\hline Aphidius colemani & 2 & 0 & 1 & 0 & 3 & 1.0 \\
\hline Ephredus plagiator & 1 & 0 & 1 & 0 & 2 & 0.7 \\
\hline Trioxys auctus & 1 & 1 & 0 & 0 & 2 & 0.7 \\
\hline Aphidius avenae & 0 & 1 & 0 & 0 & 1 & 0.3 \\
\hline Aphidius ervi & 1 & 0 & 0 & 0 & 1 & 0.3 \\
\hline Lysiphlebus fabarum & 0 & 0 & 0 & 1 & 1 & 0.3 \\
\hline
\end{tabular}

Letters within a line indicate the significant difference of abundance between treatments (pairwise test of Tukey, $p<0.05$ ). The too little numbers of lacewings did not allow performing of the analysis - Les lettres au sein d'une ligne indiquent la différence significative en termes d'abondance entre les traitements (test de comparaison de Tukey, $\mathrm{p}<0,05$ ). La trop faible abondance de chrysopes $n$ 'a pas permis de réaliser d'analyses statistiques.

(Fassotte et al., 2016). Because we did not measure the release rate of the sex pheromone in the field, we cannot exclude that the amount of semiochemicals that diffused was too low to attract $H$. axyridis.

\section{CONCLUSIONS}

In the present experiment, novel tools were tested in a region where oilseed rape is not common. The exploratory dimension of the study explains its limited design in terms of number of sites (one field), replicates (three per treatment) and study years (one season). The issues encountered here suggest that technical adjustments are needed for future work at a larger scale. First, conducting a power analysis would help sizing the experimental design (Johnson et al., 2015). Second, an earlier sowing of oilseed rape could allow its appropriate development. Third, measuring the release rate of the sex pheromone in the field could allow drawing a conclusion on its ability to attract $H$. axyridis for biological control. 


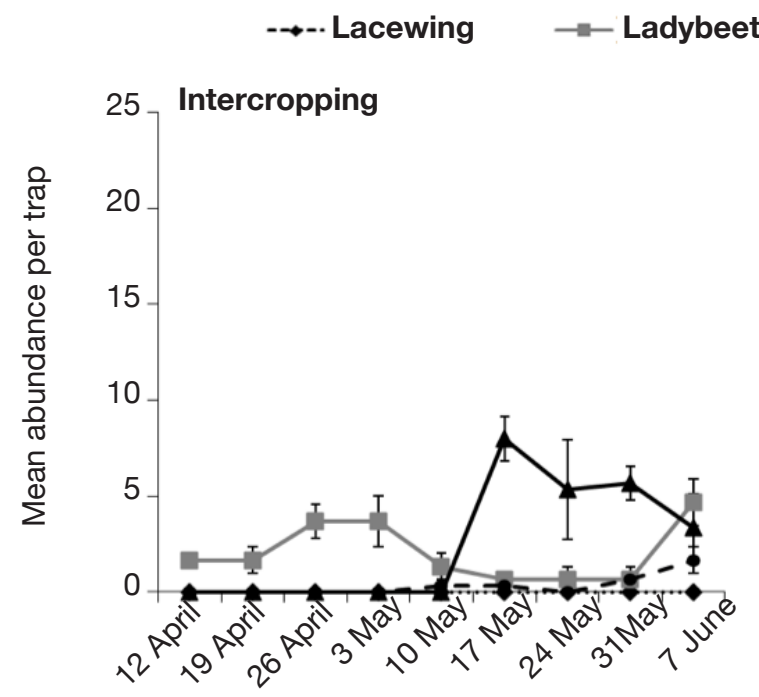

Parasitoid - - - Syrphid
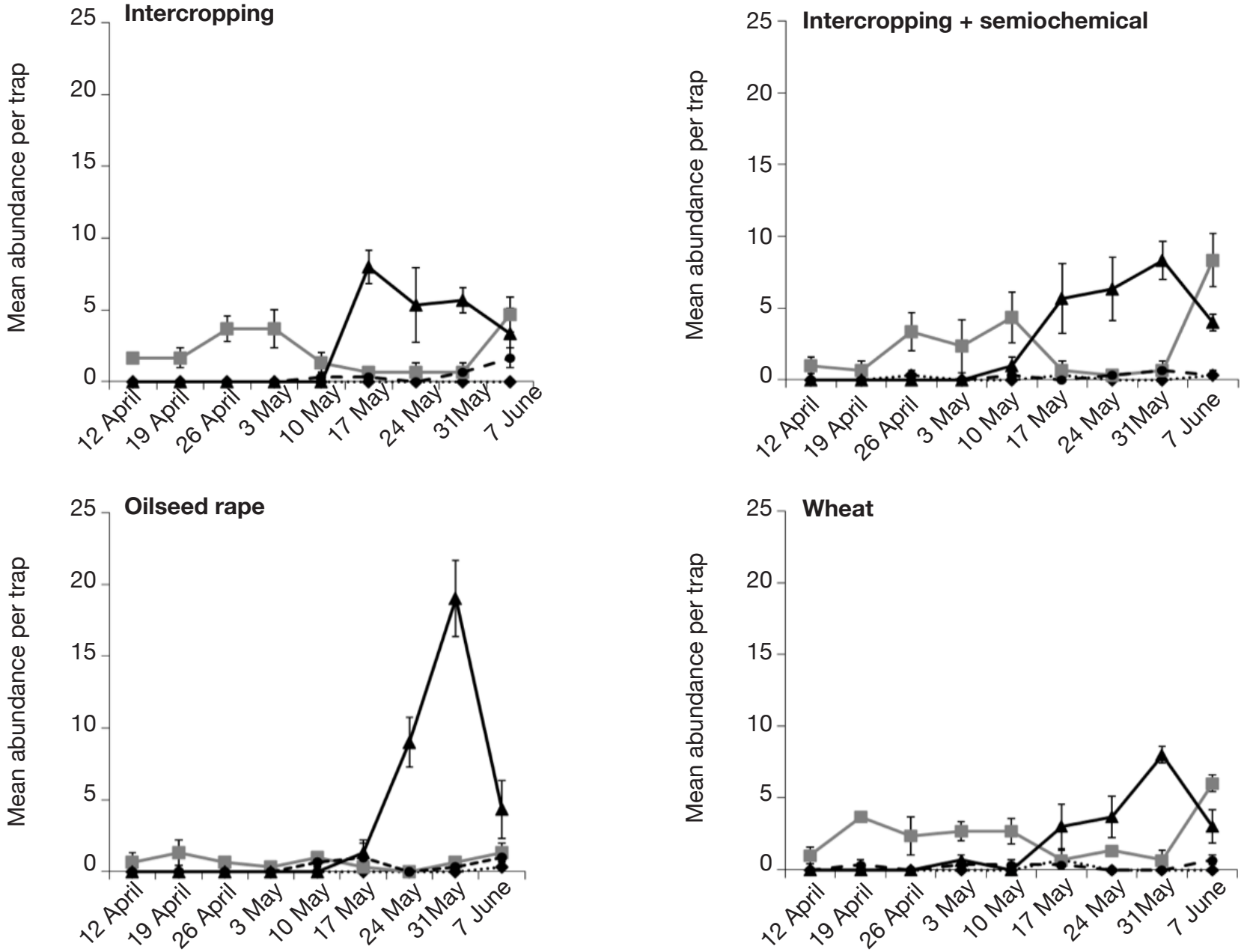

Figure 2. Mean number ( \pm SEM) per trap of lacewings (Neuroptera: Chrysopidae), ladybeetles (Coleoptera: Coccinellidae), parasitoids (Hymenoptera: Braconidae) and hoverflies (Diptera: Syrphidae) through time in the four treatments - Abondance moyenne ( \pm SEM) par piège en chrysopes (Neuroptera : Chrysopidae), coccinelles (Coleoptera: Coccinellidae), parasitoïdes (Hymenoptera : Braconidae) et syrphes (Diptera : Syrphidae) au cours du temps au sein des quatre traitements.

\section{Acknowledgements}

The authors are grateful for the technical support provided by the Langfang experimental station of the Institute of Plant Protection (CAAS), Dr Jia Fan, Mrs Jing-Rui Sun and Mr Zhong-Li Han for their help in organizing the field trial, and Dr Bérénice Fassotte for providing the synthesized blend of ladybeetle sex pheromone. This study was financially supported by the National Key R\&D Plan in China (2016YFD0300701), the Agricultural Science and Technology Innovation Program in China (ASTIP) and CARE AgricultureIsLife (University of Liège, Belgium).

\section{Bibliography}

Ali M., Saeed S., Sajjad A. \& Whittington A., 2011. In search of the best pollinators for canola (Brassica napus L.) production in Pakistan. Appl. Entomol. Zool., 46, 353-361.

Ali A., Desneux N., Lu Y. \& Wu K., 2018. Key aphid natural enemies showing positive effects on wheat yield through biocontrol services in northern China. Agric. Ecosyst. Environ., 266, 1-9.

Diepenbrock W., 2000. Yield analysis of winter oilseed rape (Brassica napus L.): a review. Field Crops Res., 67, 3549.

Fassotte B. et al., 2014. First evidence of a volatile sex pheromone in lady beetles. PLoS ONE, 9(12), e115011.

Fassotte B., Francis F. \& Verheggen F., 2016. The scent of love: how important are semiochemicals in the sexual behavior of lady beetles? J. Pest Sci., 89, 347-358.

Hatt S. et al., 2017a. Do flower mixtures with high functional diversity enhance aphid predators in wildflower strips? Eur. J. Entomol., 114, 66-76. 
Hatt S. et al., 2017b. Pest regulation and support of natural enemies in agriculture: experimental evidence of within field wildflower strips. Ecol. Eng., 98, 240-245.

Johnson P.C.D., Barry S.J.E., Ferguson H.M. \& Müller P., 2015. Power analysis for generalized linear mixed models in ecology and evolution. Methods Ecol. Evol., 6, 133-142.

Letourneau D.K., Jedlicka J.A., Bothwell S.G. \& Moreno C.R.,2009. Effects of natural enemy biodiversity on the suppression of arthropod herbivores in terrestrial ecosystems. Annu. Rev. Ecol. Evol. Syst., 40, 573-592.

Lopes T. et al., 2014. Effets de deux associations culturales à base de blé sur les populations de pucerons (Homoptera : Aphididae) et d'auxiliaires aphidiphages: étude préliminaire menée en Chine. Entomol. Faunistique = Faunistic Entomol., 67, 113-119.

Lopes T. et al., 2016a. Wheat (Triticum aestivum L.)-based intercropping systems for biological pest control: a review. Pest Manage. Sci., 72, 2193-2202.

Lopes T.et al., 2016b.Checklist of Aphidiinae (Hymenoptera: Braconidae) and Aphelinus (Hymenoptera: Aphelinidae) species from Belgium with respectively four and three new records. Zootaxa, 4092(4), 548-560.

Lundgren J.G., 2009. Relationships of natural enemies and non-prey foods. Dordrecht, The Netherlands: Springer.

$\mathrm{R}$ Core Team, 2017. R: a language and environment for statistical computing. Vienna: $\mathrm{R}$ Foundation for Statistical Computing.
Sidlauskas G. \& Bernotas S., 2003. Some factors affecting seed yield of spring oilseed rape (Brassica napus L.). Agron. Res., 1(2), 229-243.

Varennes Y.-D., Boyer S. \& Wratten S.D., 2016. Nectar from oilseed rape and floral subsidies enhances longevity of an aphid parasitoid more than does host honeydew. BioControl, 61, 631-638.

Ver Hoef J.M. \& Boveng P.L., 2007. Quasi-Poisson vs. negative binomial regression: how should we model overdispersed count data? Ecology, 88(11), 2766-2772.

Wang W.L. et al., 2009. Impact of intercropping aphidresistant wheat cultivars with oilseed rape on wheat aphid (Sitobion avenae) and its natural enemies. Acta Ecol. Sinica, 29(3), 186-191.

Wang G. et al., 2011. Combining intercropping with semiochemical releases: optimization of alternative control of Sitobion avenae in wheat crops in China. Entomol. Exp. Appl., 140(3), 189-195.

Xu Q. et al., 2018. A push-pull strategy to control aphids combines intercropping with semiochemical releases. J. Pest Sci., 91, 93-103. 